\title{
Curriculum Development in the Informing Sciences: Ecological Metaphor, Negotiation or Actor-Network?
}

\author{
Arthur Tatnall \\ Victoria University, Melbourne, Australia
}

Arthur.Tatnall@vu.edu.au

\author{
Bill Davey \\ RMIT University, Melbourne, Australia \\ BillD@rmit.edu.au
}

\begin{abstract}
Change in higher education information systems, and other informing science curricula is inevitable. This paper offers a brief consideration of three different models that can be used to describe how this change occurs. Most curriculum texts give prime consideration to approaches to curriculum change based on research, development and diffusion models, and the paper outlines some objections to the application of models of this type to describing how university curriculum in the informing sciences is built and rebuilt. It offers instead three alternate models; one based on an ecological metaphor, another on curriculum negotiations and the third on innovation translation from actor-network theory, to describe how this process occurs. This is a theoretical paper that does not advocate one model over another, and does not propose the use of any one of these models in devising a new curriculum. It is concerned only with obtaining a better understanding of how this complex process occurs.
\end{abstract}

Keywords: Curriculum changes, information systems, informing science, innovation

\section{Introduction: Models of University Curriculum Development}

Information Systems (IS), along with Information Technology (IT) and other aspects of the informing sciences, is a discipline that is subject to constant and continuing change as new technologies appear and new methodologies and development techniques are devised. IS curriculum must, of necessity, undergo frequent revision and change. This paper offers a comparison of three inter-related models that each attempt to describe how curriculum change occurs in higher education courses in the informing sciences.

A common way of attempting an explanation of the process of curriculum development is by reference to some form of research, development and diffusion model (Nordvall, 1982) in which a rational and orderly transition is posited from research to development to diffusion to adoption. Although initially proposed to explain curriculum change in schools, such models are also commonly applied to explanating the development of higher education curriculum; the subject of this paper. Models of this sort suggest that curriculum development is a logical process of matching the objectives of a particular program to curriculum elements, but we will argue that it really involves a much more complex process than this.

A related approach is to consider that many curriculum statements result from the conscious or unconscious copying of 'authoritative' existing statements, rather than from any new thought (Clements, Grimison, \& Ellerton, 1989). Although this approach, sometimes known in Australia as the 'Colonial Echo

Material published as part of these proceedings, either on-line or in print, is copyrighted by Informing Science. Permission to make digital or paper copy of part or all of these works for personal or classroom use is granted without fee provided that the copies are not made or distributed for profit or commercial advantage AND that copies 1) bear this notice in full and 2) give the full citation on the first page. It is permissible to abstract these works so long as credit is given. To copy in all other cases or to republish or to post on a server or to redistribute to lists requires specific permission from the publisher at Publisher@InformingScience.org
Model', may have some credence in considering curriculum areas such as school mathematics or history, it has been shown to have little relevance in information systems curricula (Tatnall, 1993) at the university level which, in most countries up till the mid-1980s, was developed primarily in response to local needs. Since that time, however, curriculum documents from groups like IFIP, ACM, IEEE and 
IRMA have, in many cases, tended to act as 'authoritative' statements in this way.

Writing about mathematics curriculum in Australia, Truran (1997) offers what he calls a 'Broad Spectrum Ecological Model' involving accommodating forces to explain divergence between programs. Truran proposes that educational systems may be seen as ecosystems containing interacting individuals and groups of individuals. The interaction will sometimes involve co-operation and sometimes competition, and may be interpreted in terms of these interacting forces along with mechanisms for minimising energy expenditure. Tatnall and Davey (2002) have expanded this model to provide a metaphor for IS curriculum development.

University information systems curriculum development takes place in the environment of an educational institution containing both academic and industrial elements, and also artefacts such as development tools and methodologies. We will argue that the process of curriculum development actually involves a set of complex negotiations between those writing the details of the curriculum. The 'parties' to the negotiation can include things like the 'base positions' of a number of individual academic staff, a particular programming language, a specific teaching package, filling a particular industry career-niche for students, and a specific set of 'important concepts'.

Tatnall (2000) proposes that higher education information systems curriculum can best be seen as an actor-network involving the contributions of both human and non-human actors. Actor-network theory (ANT) pictures innovation as involving the translation of any idea into new forms by potential adopters. In this model a curriculum innovation is first translated into a form appropriate to a particular higher education institution, or group of academics, that is quite probably different to the forms it appears in elsewhere.

Curriculum development is a highly complex process and this paper uses an ecological metaphor, a curriculum negotiation model, and innovation translation to investigate frameworks for understanding curriculum development in higher education informing science environments. Without some understanding of the complexities of this process, effective IS curriculum change is not possible.

\section{An Ecological Metaphor for Curriculum Development}

Borrowing concepts from the area of community and developmental ecology (Townsend, Harper, \& Begon, 2000), Truran (1997) articulates two key biological principles that underlie the discipline of ecology:

- Organisms behave in ways that optimise the balance between their energy expenditure and the satisfaction they obtain.

- Organisms operate within a competitive environment that ensures only the most efficient of them will survive.

An ecosystem can be considered to contain producers, consumers and decomposers. A classical definition is "a natural unit of living and non-living parts that interact to produce a stable system in which the exchange of materials between the living and non-living parts follows a circular path" (Ville, 1962). Habitat, ecological niches, and the exploitation of resources in predator-prey interactions, competition, and multispecies communities (Case, 2000) are all important considerations in ecology. Many different individuals and species typically occupy any given ecosystem, and they can be considered to interact in several different ways.

An ecosystem contains a high degree of complexity due to the large number of creatures and species living in it, and to the variety of interactions possible between each of these. The 'ecosystem' represented by the curriculum in a university Information Systems Department contains (at least) the following 'species': lecturers, researchers, students, professional bodies, university administrators, Course Advisory Board members and representatives of the computer industry. The 'environment' also contains many inanimate 
objects relevant to the formation of the curriculum, including: computers, programming languages, textbooks, lecture rooms, analysis and design methodologies, networks, laboratories, programming manuals, and so on.

Following earlier work by Truran (1997), Tatnall and Davey (2002) suggest that a useful correspondence may be seen between these ideas and the process of curriculum development. They argue that a university information systems curriculum may be seen as an ecosystem, and that the interactions within this ecosystem can be analysed in terms of ecological concepts such as competition models, co-operative behaviour, predator-prey relationships, niche-development and energy expenditure.

The following examples show how such a model might be applied to curriculum change. Firstly, consider the academic who argues that the IS curriculum must include some component because: "most people think ..." or "the most common programming language is ..." or "the most jobs are in ...", when perhaps their subtext is really: "I know this product well, so it must be important" or "My tenure is up and I teach this subject, so I must stress its importance" or "I dislike that person, so their work must be unimportant". This is not an attempt at cynicism but some extreme examples of what an ecologist might describe as factors influencing the evolution of a curriculum. Ecology as a framework tells us to expect progress of any task through co-operative or competitive behaviours of the animate and inanimate factors of the environment. A factor that cannot compete or co-operate is inevitably discarded.

Hence in understanding the process of curriculum development in the informing sciences we should look at the factors, both human and artefact, to see which could be expected to compete or co-operate and become part of the surviving outcome. A non-human stakeholder such as a development tool or methodology will either co-operate with the environment, compete successfully, or die out. This may mean a new curriculum element becomes incompatible with an old element and so replaces it. Alternatively it may mean that two new tools, for instance, can be used together, or that a particular curriculum element is compatible, or perhaps incompatible, with the desires and interests of a particular faculty member.

One example of the applicability of this model is exemplified in a case we have studied where a particular programming language was retained in a course despite the fact that no other university in the region taught it, and its place being challenged by more recent languages. It retained its place because the academic involved in its teaching was able to argue that it allowed the course's students to take up jobs in the small number of prominent local industries using this language: that it filled an important ecological niche.

Researchers investigating curriculum development, or any other field, must use language in framing their research questions. This language often reflects a general viewpoint from the field under investigation, and will always embody some metaphor for the principle components of this field. Many of the metaphors used in curriculum development are simple ones from areas such as manufacturing or the physical sciences, but any investigation of development processes in rapidly changing areas such as the informing sciences shows that a common factor is complexity. One discipline to have found suitable metaphors to accommodate complexity is that of ecology, and we contend that ecological principles appear to provide good descriptions of common curriculum development activities. The ease with which the metaphor can be used to describe actions within IS curriculum development shows that it can be useful as a set of language elements that might lead the researcher to framing useful questions that do not trivialise the complexity of the field.

\section{Curriculum Negotiation Leading to an Educational Product}

Many parties take part in the negotiations that result in the curriculum 'product' as it finally appears. To illustrate how these negotiations take place in the informing sciences we will consider a situation involving just three of these parties: the Course Advisory Committee for the School of Information Systems, the 


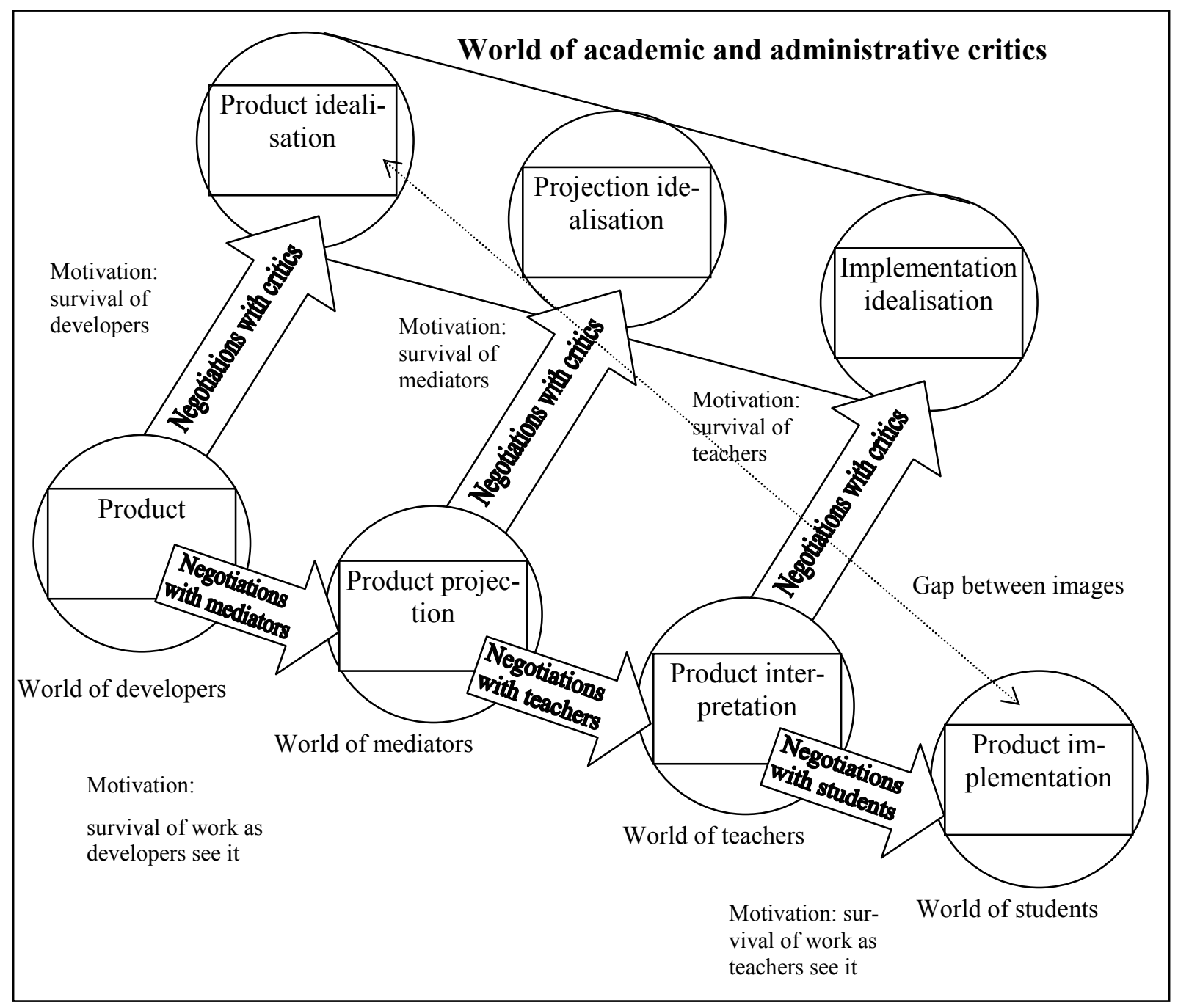

Figure 1: Adapted from Pitman's (1981) model of curriculum negotiation

IS academic teaching staff, and the university administration. Usually, a Course Advisory Committee will consist mainly of representatives from the computer industry and a professional body such as the Australian Computer Society, and will adopt the position that the university information systems curriculum should reflect the needs of the computer industry. This group will have an industry focus. The academic staff who will have to teach the curriculum will be concerned, apart from the curriculum's content, with the educational needs of their students and what can usefully be taught to them. They will have more of a teaching focus. The university administration will focus mainly on the cost and availability of the resources required to deliver the curriculum, and on the maintenance of academic standards.

The curriculum development process involves each of these groups meeting to negotiate the content of the curriculum according to the way each group sees it. This process is much more complex that just the logical selection of material deemed important to fill the needs of business or industry, or by a committee of academics, as each party will have to argue and compromise, to some extent, during the negotiations. Each party will attempt to make the most of their own viewpoint and to ensure, as far as this is possible, that the other parties give due regard to this viewpoint.

To understand and anticipate these actions, we need a broad conceptual framework. Pitman (1981) argues that the 'product' originally devised by a curriculum developer is modified in a series of negotiations with mediators, teachers and students before being adopted (see Figure 1). Pitman holds that these modifications are seen as necessary by each of these groups for the survival of the way they have of doing things. 
This model, originally developed to explain how change occurs in mathematics curriculum, indicates several places where curriculum development becomes something other than a carefully directed intellectual exercise. A slight modification of this model would see these negotiations, in the context of a university information systems curriculum, as being between the Course Advisory Committee, university academics, and university administrators.

An important aspect of this model is seeing the curriculum as a product that is produced by the joint, negotiated actions of several parties. The final product is then something that does not belong to any one of the parties, and in which all parties can find something of their own input. The model regards the final product as a true negotiation between these parties, but omits one party that we regard as essential to the negotiations: the technology itself. The next approach we will discuss will attempt to redress this omission.

\section{Curriculum Development as an Actor-Network}

Actor-network theory (Callon, 1986; Latour, 1986; Law, 1992), rather than recognising in advance supposed characteristics of humans and of social organisations and distinguishing their actions from the inanimate behaviour of technological and natural objects, adopts an anti-essentialist position in which it rejects there being some difference in 'essence' between humans and non-humans. In ANT an actor is any human or non-human entity that is able to make its presence individually felt by the other actors. An actor is made up only of its interactions with these other actors and Law (1992) remarks that an actor thus consists of an association of heterogeneous elements constituting a network. Callon (1986) notes that an actor can also be considered, at times, as a black box, as we do not always need to see the details of the network of interactions inside it.

The model of translation as proposed in actor-network theory proceeds from a quite different set of assumptions to those used in innovation diffusion (Rogers, 1995). Latour (1986) maintains that in an innovation translation model the movement of an innovation through time and space is in the hands of people, each of whom may react to it in different ways. In this case the adoption of an innovation comes as a consequence of the actions of everyone in the chain of actors who has anything to do with it. Furthermore, each of these actors shapes the innovation to their own ends, but if no one takes up the innovation then its movement simply stops.

McMaster et al. (1997) add that innovations do not wait passively to be invented or discovered, but are instead created: "... from chains of weaker to stronger associations of human and non-human alliances. ... Each actant translates and contributes its own resources to the shape and ultimate form of the emerging black box" (McMaster et al., 1997 :4). This occurs, they note, by virtue of the 'relative convergences' of their respective interests. Latour (1986) stresses that it is not just a matter of each of the actors in the chain either resisting the innovation or transmitting it in the form they received it, but that their shaping of the innovation is essential for its continued existence. In this they are actors, not just clients, and everyone involved translates, or shapes the innovation according to their own needs.

A translation model requires the focus to be on understanding how actor-networks are created, strengthened and weakened, rather than on causes and effects. The key to innovation is the creation of a powerful enough consortium of actors to carry it through. Getting an innovation accepted calls for strategies aimed at the enrolment of others. Latour (1986) maintains that this is done by 'interesting' others and then getting them to follow our interests, so becoming indispensable to them.

As an example of the investigation of educational innovation using ANT we will briefly relate the introduction of the programming language Visual Basic (VB) into the information systems degree at an Australian university (Tatnall, 2000; Tatnall \& Davey, 2001). The story begins when Fred, a university IS academic, first encountered VB when working on an external consulting job. Fred was so impressed that 
he decided he must introduce VB to his students. The particular subject taken by Fred where he intended introducing VB was one involving systems design. It was not a programming subject and this meant that only the 'visual' aspect of VB was needed. Fred worked for VB's introduction by enrolling a number of allies including other academics, the course advisory committee, his students, and the computing laboratories where the teaching of the subject using VB was to take place. (ANT speaks of the 'enrolment of the laboratories' when it is referring to the need to attend to all the things that might otherwise cause physical laboratory constraints to be a problem to VB's introduction.) When adopting VB into this subject, as only some aspects (- the visual parts) were required it was translated, by Fred, from a general purpose programming language into a package for screen design. In this way the Visual Basic he adopted for this subject should be seen as a different innovation to the VB used in teaching programming in a computer science course.

\section{Conclusions: Ecology, Negotiation or Actor-Network?}

Curriculum development in the informing sciences is a complex process, and one that cannot simply be explained by reference to a set process of referring new ideas to a series of university committees. The choices of individual academics, or groups of academics, to adopt or ignore a new concept or technology, and to compete or co-operate, must also be considered. This inevitably involves a negotiation process between many different actors. This negotiation process can be described and analysed in several different ways: as a behaviour in an ecology, a curriculum negotiation process leading to an educational product, or an actor-network. This paper has briefly outlined these three approaches to description of the curriculum development process, and has shown them to be quite closely related. We will leave to the reader any judgement on which best describes the real situation.

\section{References}

Callon, M. (1986). The Sociology of an Actor-Network: The Case of the Electric Vehicle. In M. Callon \& J. Law \& A. Rip (Eds.), Mapping the Dynamics of Science and Technology (pp. 19-34). London: Macmillan Press.

Case, T. J. (2000). An Illustrated Guide to Theoretical Ecology. New York: Oxford University Press.

Clements, M. A., Grimison, L. A., \& Ellerton, N. F. (1989). Colonialism and School Mathematics in Australia 1788-1988. Paper presented at the School Mathematics conference: The Challenge to Change Geelong, Geelong, Australia.

Latour, B. (1986). The Powers of Association. In J. Law (Ed.), Power, Action and Belief. A new sociology of knowledge? Sociological Review monograph 32 (pp. 264-280). London: Routledge \& Kegan Paul.

Law, J. (1992). Notes on the Theory of the Actor-Network: Ordering, Strategy and Heterogeneity. Systems Practice, 5(4), 379393.

McMaster, T., Vidgen, R. T., \& Wastell, D. G. (1997, 9-12 August, 1997). Towards an Understanding of Technology in Transition. Two Conflicting Theories. Paper presented at the Information Systems Research in Scandinavia, IRIS20 Conference, Hanko, Norway.

Nordvall, R. C. (1982). The process of change in higher education institutions (ERIC/AAHE Research Report 7). Washington DC: American Association for Higher Education.

Pitman, A. (1981). The Necessary Distortion of Disseminated Innovations. Journal of Curriculum Studies, $13(3), 253-265$.

Rogers, E. M. (1995). Diffusion of Innovations (4 ${ }^{\text {th }}$ edition). New York: The Free Press.

Tatnall, A. (1993). A Curriculum History of Business Computing in Victorian Tertiary Institutions from 1960 - 1985. Deakin University, Geelong.

Tatnall, A. (2000). Innovation and Change in the Information Systems Curriculum of an Australian University: a SocioTechnical Perspective, Central Queensland University, Rockhampton.

Tatnall, A., \& Davey, B. (2001, 19-22 June 2001). How Visual Basic Entered the Curriculum at an Australian University: An Account Informed by Innovation Translation. Paper presented at the Challenges to Informing Clients: A Transdisciplinary Approach (Informing Science 2001), Krakow, Poland. 
Tatnall, A., \& Davey, B. (2002). Information Systems Curriculum Development as an Ecological Process. In E. Cohen (Ed.), IT Education: Challenges for the $21^{\text {st }}$ Century. Herchey, PA: Idea Group Publishing.

Townsend, C. R., Harper, J. L., \& Begon, M. (2000). Essentials of Ecology. Massachusetts: Blackwell Science.

Truran, J. M. (1997, 7-10 December). Reinterpreting Australian Mathematics Curriculum Development Using a Broadspectrum Ecological Model. Paper presented at the Old Boundaries and New Frontiers in Histories of Education: Australian and New Zealand History of Education Society Conference, Newcastle, Australia.

Ville, C. A. (1962). Biology. Philadelphia: W.B. Saunders Company.

\section{Biography}

Arthur Tatnall is a Senior Lecturer in the School of Information Systems at Victoria University in Melbourne, Australia. He holds bachelors degrees in science and education and a research master of arts in which he explored the origins of business computing education in Australian universities. His $\mathrm{PhD}$ involved a study in curriculum innovation in which he investigated the manner in which Visual Basic entered the curriculum of an Australian university. His research interests include technological innovation, information systems curriculum, Visual Basic programming, project management, electronic commerce, and information technology in educational management.

Bill Davey is a Senior Lecturer in the School of Business Information Technology at RMIT University, Melbourne, Australia. He holds bachelors degrees in science and education and a master of business degree. His research interests include methodologies for systems analysis and systems development, Visual Basic programming, information systems curriculum, and information technology in educational management.

Arthur and Bill have worked together and co-operated on many occasions. They have worked on joint research projects and co-authored a large number of papers, book chapters, and textbooks relating to management information systems, programming and IS curriculum. 